national nuclear information service based on Vienna. The proposal has been widely discussed over the past few years, but has not yet been finally agreed. The Soviet Union does have its own information retrieval system, called Viniti, and has done some fundamental studies of language and mechanization. But it is not clear exactly what stage the Russian system has reached. Mr John Grey, of the British Office of Scientific and Technical Information, says that to produce an effective international system it would be necessary to produce standard formats and procedures, as well as compatible indexing systems and programmes. With the third generation of computers, he hopes that this will be very much easier, but he stresses that all systems are still experimental and that the next two or three years are likely to be of crucial importance for international collaboration. "There can't be too much discussion on it," he said.

\section{Culham Divided}

IT now seems probable that the Science Research Council will be taking over responsibility for at least part of Culham Laboratory. Dr Robert Wilson, who is director of the group at Culham working on astrophysics, says that "agreement has been reached in principle" for the phased take-over of his group by the SRC. But he emphasizes that consultations are by no means complete, and there are a number of questions connected with the staff which still have to be settled. If the transfer can be made, it will do something to restore optimism at Culham-since the Minister of Technology, Mr Anthony Wedgwood Benn, announced in July the decision to cut the laboratory's expenditure by 10 per cent a year for five years, there has been something of an air of gloom. Because the astrophysical work was supported from the fusion budget, it was as vulnerable as any other project at the laboratory.

If the discussions go well, the astrophysical group will be converted to an SRC unit based at Culham. This process should be complete by April 1969, and the group will remain at Culham at least until 1971. The group consists of 18 professionals and 10 others, and the annual budget has been running at something like f0.25 million a year. (This is not a hard and fast figure, because it includes overheads and some laboratory plasma work which the SRC may not take over. The exact financial commitment of the SRC will not be clear until the negotiations are complete.) As well as studying the solar spectrum with stabilized Skylark rockets, the group has been responsible for the measurement of new spectral lines and of atomic cross-sections. It now hopes to move on to stellar spectroscopy, with rockets stabilized on stars.

So far, nothing has been decided about the team which is working on the design of a large astronomical telescope for ESRO. This is a different team, consisting of 25-30 professionals working part time. As yet, the decision is not urgent, because ESRO has not decided whether to proceed with the project. If the LAS project does proceed, Dr Wilson says, the position of the team working on the design will have to be considered.

There is little doubt that the move to the SRC will make for better co-ordination of the British space research programme, but there is no particular reason to believe that money will then be easier to come by. The programme will have to find its own level within the competitive atmosphere of the SRC. As a number of commentators-Nature among them-have suggested, a move to the SRC might be the answer for the whole of the Culham establishment. But there has so far been no hint of that.

\section{Facing the Future with $\mathrm{SI}$}

A CONFERENCE of editors of British scientific journals adopted on December 11 a recommendation that editors should collectively encourage the use in scientific journals of the system of metric units known as SI (which is an abbreviation for Système International d'Unités). A document prepared during the past six months by a working party under Professor James Lighthill has produced a detailed list of definitions and suggestions including, in particular, the view that "the journals devoted to science and engineering should seize the opportunity of playing a crucial role in helping to end the confusion and wastefulness (both mental and material) resulting from the present multiplicity of units". This decision has been given the encouragement and the blessing of the Ministry of Technology, which is now hoping for more or less complete metrification of the British system of weights and measures by the mid-seventies.

The basic units of the SI system are the metre $(\mathrm{m})$, kilogramme (kg), second (s), ampere (A), degree Kelvin $\left({ }^{\circ} \mathrm{K}\right)$ and candela (cd). Allowable derivatives include the Joule $(J)$ but not the calorie, the weber $(\mathrm{Wb})$ but not the Gauss, the hertz $(\mathrm{Hz})$ but not the cycle per second and the degree Celsius $\left({ }^{\circ} \mathrm{C}\right)$ but not the degree Centigrade (which is said to be one of the points on which French delegates to the international conferences have placed a great deal of emphasis). One of the characteristics of the SI system is that fractions and multiples of units should wherever possible be quoted to the nearest integral or fractional multiple of a thousand, which means that the Angstrom $\left(10^{-10} \mathrm{~m}\right)$ is banned and even the centimetre $\left(10^{-2}\right)$ is frowned on. Needless to say, the foot, the pound, the gallon and the Btu have nothing said in their defence.

By all accounts, a great many British journals have already agreed to regard 1968 as a period of experiment and of transition. Although the document produced by the working party (see Nature next week for further details) seems to have obtained a sympathetic reception, it remains to be seen how many journals will follow Professor Lighthill's suggestion that they should, after a suitable warning period, automatically return manuscripts in units other than SI.

\section{ELDO Fails Again

$$
\text { from Angela Croome }
$$

Aцтночян the political crises for co-operative European space enterprises took place in 1966, the technological failures which give a gloss of justification to the political wrangling have occurred this year. There were the pre-launch troubles with the first ESRO (European Space Research Organization) satellite in the spring which have made necessary a year's postponement in the launching of the backup vehicle and considerable extra cost. Now the two ELDO shots of the 
year, designated Flight $6 / 1$ and $6 / 2$, have both failed. The second of these flight tests from Woomera took place last week on December 5. ELDO, the European Launcher Development Organization, is concerned with space tools and not research. The two launches were stages in the development of a large carricr rocket based on the British Blue Streak for European purposes.

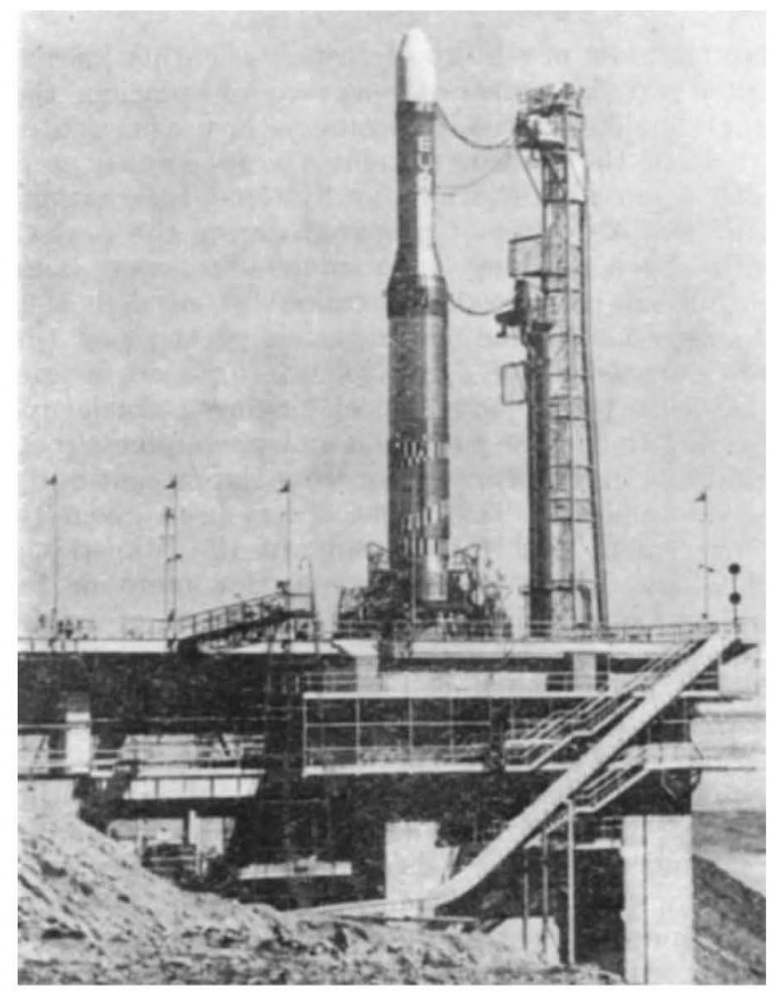

Europa I in launch position (ELDO photograph)

The failure of the second launch has marked similarities with that of $F 6 / 1$ on September 2 . In both cases the programme sequencer was implicated. This is mounted on the French second stage and both its manufacture and its checkout are French responsibilities. The cause of last week's vehicle failure was very simple: the programme-sequencer did not start at take-off and did not work at all during the few minutes' flight. Consequently the second stage (Coralie) did not separate and because it did not separate it did not fire. The second stage electronics failure on September's F6/1 test was more complex. Then the sequencer malfunctioned briefly-possibly for as short a time as 200 milliseconds-during the first/second stage separation phase as Blue Streak boost ended. The consequence was that although the second stage separated it did not fire and a few seconds later was automatically destroyed. On both the $F 6$ flights the Bluc Streak booster stage functioned "normally", as it has done on the preceding five flight tests.

Apart from giving the first "live" test to the second stage, the objective of $F 6 / 2$ was an operational run of the complete ground network for control and tracking. This was partially achieved. The upper parts of both this year's flight vehicles, representing the German third stage and the Italian test satellite, were dummies though of correct weight and aerodynamic characteristics. Despite the setbacks with the second stage, there is apparently to be no change in the firing schedule for which 12 flight tests of the Europa I configuration extending through to 1970 are laid down. The next flight ( $F 7)$, due next summer, will have all tbree rocket stages live and will be the first potential orbital flight though not carrying a fully instrumented satellite. Clearly the French will have to do some intensive homework to avoid frustrating this trial and its successors. The $F 6$ booster has already completed its tethered test firings at Spadeadam (Cumberland) and is being made ready for shipment from Hawker Siddeley's Hatfield works.

The still distant $F 11$ and $F 12$ orbital tests may carry components of the perigee/apogee system (PAS) - the key element in converting Europa I into Europa IIor a low polar orbit into the high equatorial type favoured for communications satellites. France heads the list of intending buyers of the Europa II launcher on which she is dependent for her ambitious plans of direct French communications to link metropolitan France with French-speaking territories overseas (SAFRAN and SAROS). Enhanced reality was given to the PAS project last week by the formation of an industrial management company representing the 11 European companies involved in its development for ELDO. Called SETIS (for Société Européenne pour l'Etude et l'Intégration des Systèmes Spaciaux) with a full-time technical staff drawn from these firms, a French president and a Paris headquarters, its chief task will be the coordination and integration of work on PAS̆. The firms involved are: Hawker Siddeley, Rolls Royce (Britain); SEREB (France); Bölkow, Erno (Germany); C.I.A. (Italy); A.C.E.C., M.B.L.E. and B.T.M.C. (Belgium); Philips and Fokker of Holland.

\section{No Joy for Euratom}

Eunatom struggles from erisis to crisis. The latest misfortune to assail the organization is a drastic budget cut, enforced last Friday at the Council of Ministers in Brussels. Although the Euratom commission had proposed a budget of $\$ 82$ million, the ministers cut this down to $\$ 40.695$ million after discussions which lasted all day. Even the commission's proposal was modest in comparison with earlier years, when the budget has run at about $\$ 90$ million.

The budget cuts are only the visible symptoms of a malaise which now threatens the whole future of the organization. As is reported elsewhere in this issue, the Dragon reactor project, by general agreement a successful example of co-operation, is threatened by the inability of Euratom to determine its research programme for 1968. This kind of project, in which Euratom contributes but is not wholly in control, seems to have been a main topic for argument when the ministers met last Friday. All that could be agreed was that these projects would be further considered in the next few months, but no provision was made for them for 1968 . At the meeting, France and Italy were both attempting to cut back the budget, while West Germany and Holland supported the commission and Belgium and Luxembourg remained neutral. With the refusal to sanction work on association projects, the only work 